\title{
Acute appendicitis complicated by septic mesenteric vein thrombophlebitis in an adult
}

\author{
Manisha Jana $\cdot$ Smriti Hari
}

Published online: 23 August 2011

(C) Indian Society of Gastroenterology 2011

A 43-year-old man presented with acute right iliac fossa pain and mild fever for last 3 days. Contrast-enhanced computed tomography scan (CECT) of the abdomen revealed acute appendicitis with associated mesenteric vein thrombophlebitis (Fig. 1). He was treated with intravenous antibiotics, low molecular weight heparin, and supportive treatment. He underwent interval appendectomy after 2 months.

Pylephlebitis or thrombophlebitis of the portal venous system is a rare complication usually resulting from septic conditions of the portal drainage area. Common causes include colonic diverticulitis, acute appendicitis, inflammatory bowel disease, acute cholangitis, suppurative pancreatitis, pelvic infections or bowel perforation $[1,2]$. The reported mortality is high $(30 \%$ to $50 \%)$ especially in children, because of nonspecific clinical findings and delay in diagnosis [2].
M. Jana $(\triangle) \cdot$ S. Hari

Department of Radiodiagnosis,

All India Institute of Medical Sciences,

Ansari Nagar, New Delhi 110 029, India

e-mail: manishajana@gmail.com

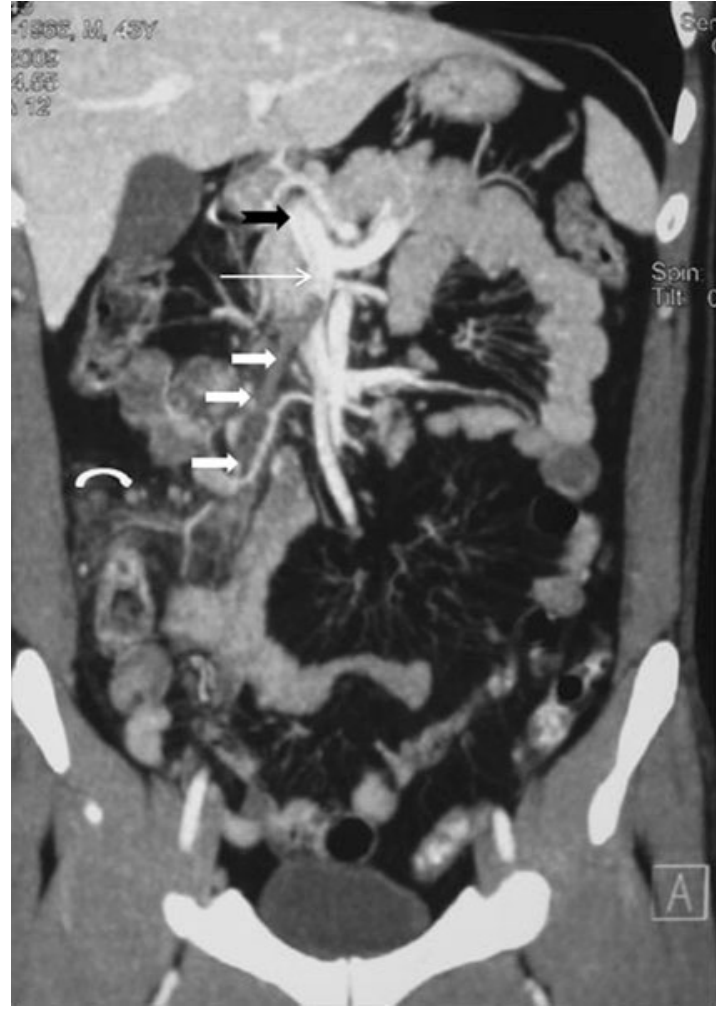

Fig. 1 Coronal reformatted CECT image reveals non-enhancing filling defect in the ileocolic vein (block arrows) extending in to the superior mesenteric vein (arrow) suggestive of thrombus. Extensive pericecal inflammatory changes (curved arrow) are also present. The extrahepatic portal vein is shown with a notched black arrow

\section{References}

1. Chang YS, Min SY, Joo SH, Lee SH. Septic thrombophlebitis of the porto-mesenteric veins as a complication of acute appendicitis. World J Gastroenterol. 2008;14:4580-2.

2. Plemmons RM, Dooley DP, Longfield RN. Septic thrombophlebitis of the portal vein (pylephlebitis): diagnosis and management in the modern era. Clin Infect Dis. 1995;21:1114-20. 